\title{
Ultra-radical surgery in ovarian cancer
}

Epithelial ovarian cancer, tubal cancer, and primary peritoneal cancer are the most significant causes of gynecologic cancerrelated morbidity and mortality. Multidisciplinary integrative team, including gynecologic oncologists, medical oncologists, surgical oncologists, pathologists, diagnostic radiologist, nuclear medicine, anesthesiologist, oncology nurses, etc. are needed to improve the outcome of these diseases. Recent advances in the understanding of the molecular biology and etiology of these cancers, diagnostic techniques and new biologic agents contributed to improved clinical outcome. Nevertheless, complete and effective surgical management stands as the most important cornerstone of both diagnosis and treatment.

Recently, the continued evolution of innovative surgical techniques and management paradigms has mandated this endeavor to arrange and describe the specific management of patients with ovarian cancer related to peritoneal surface malignancy.

These special series include extensive ovarian surgical techniques for the management of the right upper quadrant, left upper quadrant, porta hepatis, pelvis, and new techniques for the management of peritoneal disease such as hyperthermic intraperitoneal chemotherapy (HIPEC) or pressurized intraperitoneal aerosol chemotherapy (PIPAC). Also, these include important issues for the management of advanced ovarian cancer such as prediction of optimal surgery, enhanced recovery after surgery (ERAS), interventional radiological management for lymphatic leakages after gynecologic surgery.

The effective surgical management of ovarian cancer is dependent on multiple factors, including the general medical condition of the patient, the extent and biologic aggressiveness of the disease, cooperative surgical oncology, an appropriately skilled care team, and the surgeon with technique, experience, and conviction for the maximum operative effort. I hope this series will help improve the rate of survival of advanced ovarian cancer patients.

\section{Acknowledgments}

Funding: None.

\section{Footnote}

Provenance and Peer Review: This article was commissioned by the editorial office, Gland Surgery for the series "Ultra-Radical Surgery in Ovarian Cancer: Surgical Techniques for Gynecologic Oncologist”. The article did not undergo external peer review.

Conflicts of Interest: Both authors have completed the ICMJE uniform disclosure form (available at http://dx.doi.org/10.21037/ gs-2021-01). The series "Ultra-Radical Surgery in Ovarian Cancer: Surgical Techniques for Gynecologic Oncologist" was commissioned by the editorial office without any funding or sponsorship. Dr. SYP and Dr. JWK served as the unpaid Guest Editors of the series. The authors have no other conflicts of interest to declare.

Ethical Statement: The authors are accountable for all aspects of the work in ensuring that questions related to the accuracy or integrity of any part of the work are appropriately investigated and resolved.

Open Access Statement: This is an Open Access article distributed in accordance with the Creative Commons AttributionNonCommercial-NoDerivs 4.0 International License (CC BY-NC-ND 4.0), which permits the non-commercial replication and distribution of the article with the strict proviso that no changes or edits are made and the original work is properly cited (including links to both the formal publication through the relevant DOI and the license). See: https://creativecommons.org/licenses/bync-nd/4.0/. 


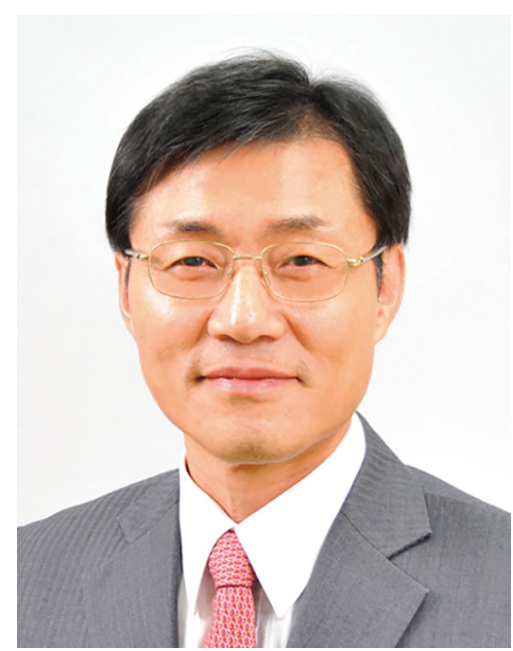

Sang-Yoon Park

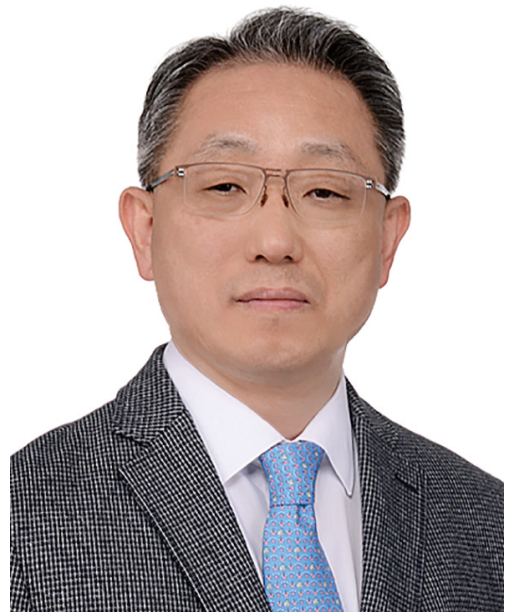

Jae-Weon Kim

Sang-Yoon Park ${ }^{1}$

${ }^{1}$ Center for Gynecologic Cancer, Graduate School of Cancer Science and Policy, National Cancer Center, Goyang, Korea. (Email: parksang@ncc.re.kr)

Jae-Weon $\mathrm{Kim}^{2}$

${ }^{2}$ Department of Obstetrics and Gynecology, Seoul National University College of Medicine, Seoul, Korea.

(Email: kjwksh@snu.ac.kr)

Submitted Jan 16, 2021. Accepted for publication Feb 04, 2021.

doi: $10.21037 / \mathrm{gs}-2021-01$

View this article at: http://dx.doi.org/10.21037/gs-2021-01

Cite this article as: Park SY, Kim JW. Ultra-radical surgery in ovarian cancer. Gland Surg 2021;10(3):1171-1172. doi: 10.21037/ gs-2021-01 